\title{
Experimental study of the strengthening effect of reinforced concrete columns jacketed under service load level
}

\author{
Pavlo Krainskyi ${ }^{1}$, Yaroslav Blikharskyy ${ }^{2,}{ }^{*}$, Roman $\mathrm{Khmil}^{1}$, and Zinoviy Blikharskyy ${ }^{1}$ \\ ${ }^{1}$ Lviv Polytechnic National University, Department of Building Constructions and Bridges, 79013, \\ Lviv, Ukraine \\ ${ }^{2}$ Lviv Polytechnic National University, Department of Highways and Bridges, 79013, Lviv, Ukraine
}

\begin{abstract}
The need of structural retrofitting and strengthening of different buildings, engineering structures or their elements is always present. Among the main reasons are demages and material deterioration due to aging, improper maintenance or physical damages; planed repairs; reconstruction or extension of the building; technical modification or complete change of operations inside the building or the structure, etc. In some cases operation of the building during retrofitting or strengthening of its structures has to be partially or fully stopped. In other cases the strengthening process takes place while the building is still operational which means that structures are strengthened under service loads. The main goal of this research is to determine the strengthening effect of reinforced concrete jacketing applied to columns under service load level. For that the experimental study of six reinforced concrete columns were carried out: four reference columns, both strengthened by jacketing and unstrengthened and two strengthened under service load. The main results of the research are presented.
\end{abstract}

\section{Main goal of the research}

Reinforced concrete jacketing is one of the traditional and widespread methods of RC structures strengthening. RC jacketing can be applied to both flexural and compressed members and has some significant advantages. Jacketed member usually do not need additional corrosion or fire protection.

A lot of research have been carried out to determine the stress-strain state of the jacketed RC members [1-3], bonding and surface preparation influence on the performance of jacketed structure [4] and seismic retrofitting using RC jacketing [5, 6]. Nevertheless the further study of this type of strengthening is relevant, since there is little known about the performance of the structures strengthened under loads of different magnitude.

In this study we try to experimentally determine the effect of initial loading, which is present during strengthening process, on further work of jacketed RC column. Reinforced concrete columns strengthened under service load are the main object of this research.

* Corresponding author: yaroslav.z.blikharskyy@1pnu.ua 


\section{Research methodology}

\subsection{Test specimen description and material properties}

For this study six test specimen of reinforced concrete columns were prepared. The overall dimensions of the test specimens presented on Fig. 1. The length of the columns was $2.2 \mathrm{~m}$ and a cross section dimensions before jacketing was $0.14 \mathrm{~m} \times 0.18 \mathrm{~m}$. Columns were tested as compressed-bent elements and were manufactured with corbels on both ends for that purpose. Cross section dimensions of the jacketed columns were increased to $0.2 \mathrm{mx}$ $0.26 \mathrm{~m}$.
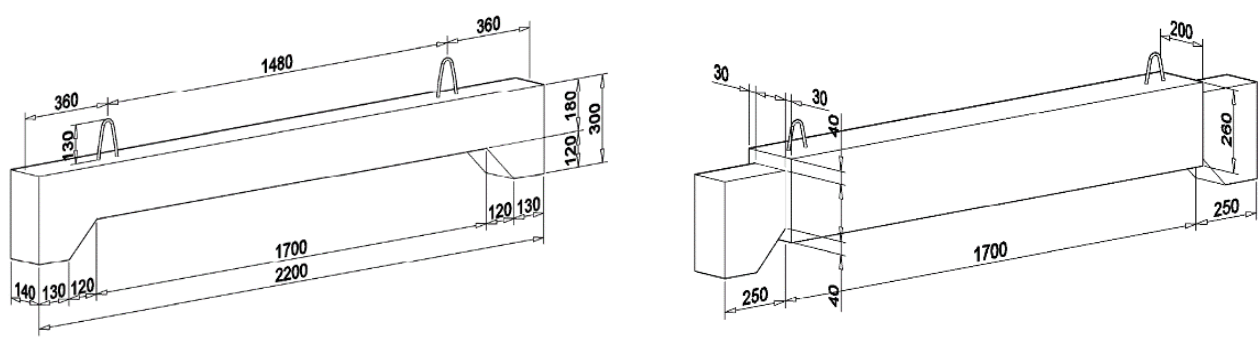

Fig. 1. Dimensions of the reinforced concrete columns test specimens.

All six columns were manufactured from the same materials. Material specimens were selected and tested to determine the mechanical properties. For cross section dimensions and reinforcement details see Fig. 2 a, b. Reinforcement ratio of unstrengthened column equaled $1.8 \%$. Four $12 \mathrm{~mm}$ rebar were used as longitudinal reinforcement with $6 \mathrm{~mm}$ rebar used for ties. The rupture stress of main rebar was $720 \mathrm{MPa}$; yield stress $-630 \mathrm{MPa}$; Young's modulus - 210GPa. Average concrete cube strength equaled $37 \mathrm{MPa}$ which corresponds to $\mathrm{C} 25 / 30$ concrete class.

Reinforced concrete jacketing length equaled $1.7 \mathrm{~m}$. Reinforcement ratio equaled $1.17 \%$. Four $10 \mathrm{~mm}$ rebar were used as jacketing longitudinal reinforcement (Fig. 2, 3) with $6 \mathrm{~mm}$ rebar used for ties. Mechanical properties of concrete and rebar were the same as previous. The preparation of the concrete surface before jacketing consisted only from dust removal and ample hydratation.

a)

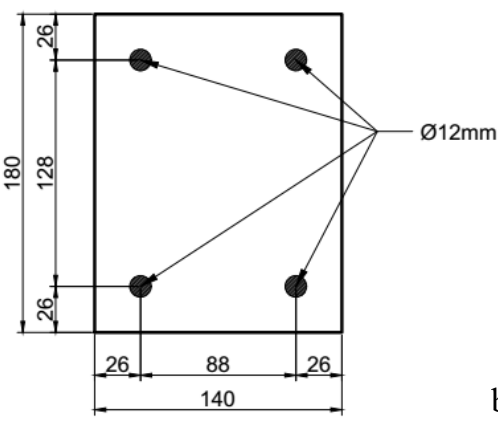

b)

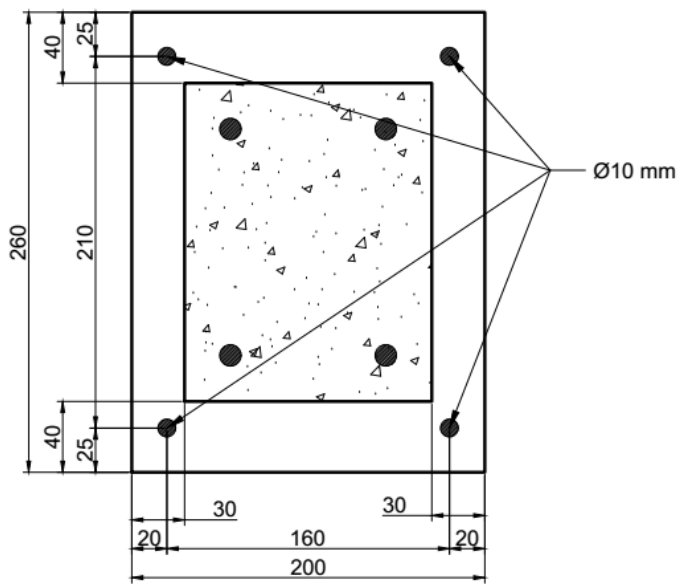

Fig. 2. Cross section dimensions and reinforcement details of unstrengthened (a) and strengthened (b) column specimen. 


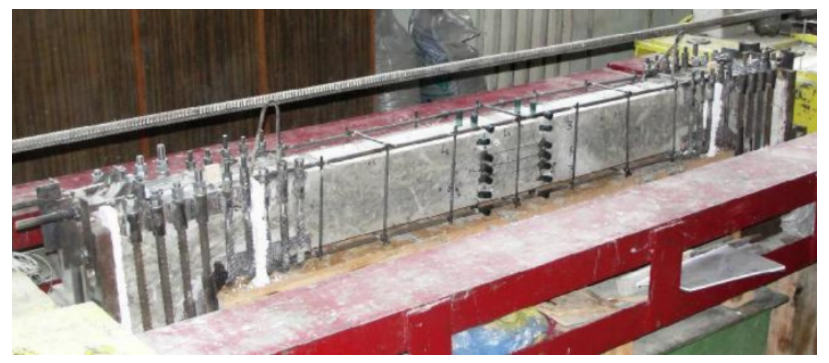

Fig. 3. Reinforcement details of strengthened column specimen.

\subsection{Experimental program}

The first two columns $\mathrm{C}-1$ and $\mathrm{C}-2$ were reference columns. They were tested without strengthening to determine the bearing capacity of the specimen and to adopt the service load value for the next tests.

Columns C-3-0 and C-4-0 were also reference columns. They were tested after strengthening but without any initial load. Bearing capacity of this specimens was considered as maximum possible and was used for comparison of the strengthening effect of the following jacketed columns.

Columns C-5-S and C-6-S were initially loaded to a service load which was adopted as $65-70 \%$ of $\mathrm{C}-1$ and $\mathrm{C}-2$ reference columns bearing capacity. After that they were strengthened and tested to failure.

Columns were tested with pinned supports. Load was applied incrementally as a force on one of the supports. The following data was acquired during the tests of the columns: strain in the rebar; strain on the compressed face of the concrete; deflection of the midheight of the column.

\section{Results of the experimental study}

\subsection{C-1, C-2 reference columns}

C-1 and C-2 columns were tested to failure without strengthening. Specimens failed in flexural manner. Average bearing capacity of two specimens equaled $175 \mathrm{kN}$. From Fig. 4

$$
\mathrm{C}-1, \mathrm{C}-2
$$

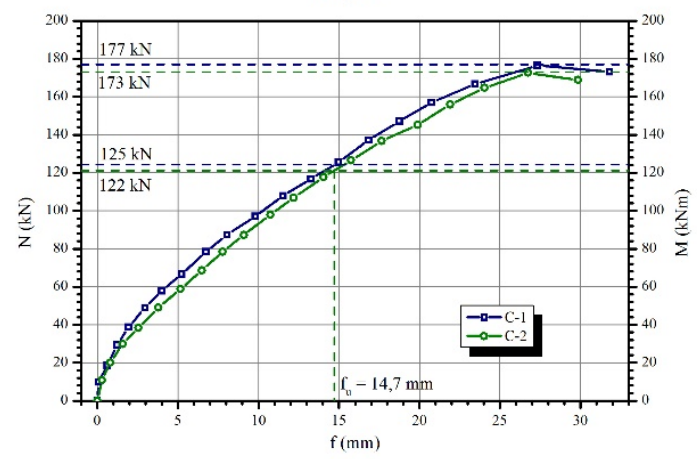

Fig. 4. C-1 and C-2 deflection at midheight plot. 
we can see that the loads that corresponded to a maximum allowed deflection of $14.7 \mathrm{~mm}$ (calculated according to Ukrainian codes for serviceability limit state) were $122 \mathrm{kN}$ and $125 \mathrm{kN}$. Considering these values we adopted a service loads for following tests of $120 \mathrm{kN}$.

\subsection{C-3-0, C-4-0 reference columns}

C-3-0 and C-4-0 columns were strengthened without initial loading and tested to failure. Specimens failed in flexural manner. Average bearing capacity of two specimens equaled $475 \mathrm{kN}$. It is 2.7 times bigger than the bearing capacity of C-1 and C-2 (see Fig. 5). We consider it to be a maximum possible effect from strengthening since there were no initial stresses or deformations in the columns before strengthening.

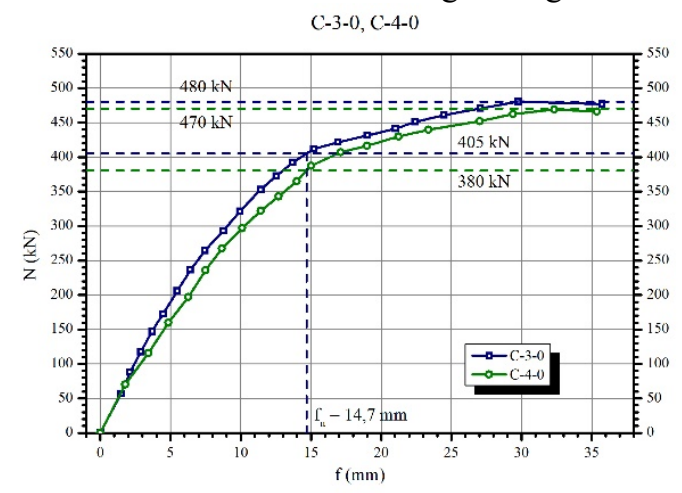

Fig. 5. C-3-0 and C-4-0 deflection at midheight plot.

\subsection{C-5-S, C-6-S columns}

C-5-S and C-6-S columns were initially loaded to a service load of $120 \mathrm{kN}$, strengthened an then tested to failure. Specimens failed in flexural manner. Average bearing capacity of two specimens equaled $430 \mathrm{kN}$. It is $90 \%$ of a maximum possible effect and 2.6 times bigger than the bearing capacity of $\mathrm{C}-1$ and C-2 (see Fig. 6). Although the application of the reinforced concrete jacketing was almost at the verge of exceeding the serviceability limit state requirements, we still achieved some positive effect in deflection manner of the columns. on Fig. 5 we can see the increase in stiffness of the columns immediately after strengthening. This resulted in a very slow increase in deflections on first steps of loading after jacketing and 1.5 times increase in serviceability capacity.

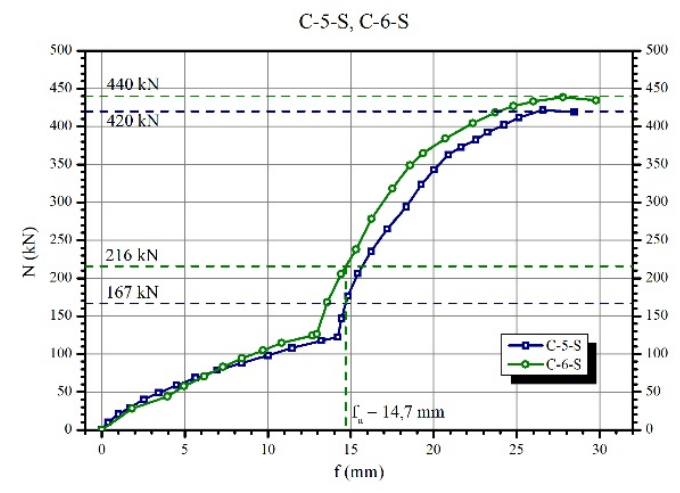

Fig. 6. C-5-S and C-6-S deflection at midheight plot. 
For comparison of all specimens the experimental data was summarized in the table 1.

Table 1. Results of research.

\begin{tabular}{|c|c|c|c|c|c|c|}
\hline \multirow{2}{*}{ Specimens } & \multicolumn{2}{|c|}{ Initial load, kN } & \multicolumn{2}{|c|}{$\begin{array}{c}\text { Bearing capacity, } \\
\mathbf{k N}\end{array}$} & \multicolumn{2}{|c|}{$\begin{array}{l}\text { Strengthening } \\
\text { effect, } \%\end{array}$} \\
\hline & specimen & average & specimen & average & specimen & average \\
\hline $\mathrm{C}-1$ & - & \multirow{2}{*}{ - } & 177 & \multirow{2}{*}{175} & - & \multirow{2}{*}{ - } \\
\hline $\mathrm{C}-2$ & - & & 173 & & - & \\
\hline $\mathrm{C}-3-0$ & 0 & \multirow{2}{*}{0} & 480 & \multirow{2}{*}{475} & 175 & \multirow{2}{*}{172} \\
\hline C-4-0 & 0 & & 470 & & 169 & \\
\hline C-5-S & 118 & \multirow{2}{*}{120} & 420 & \multirow{2}{*}{430} & 142 & \multirow{2}{*}{146} \\
\hline C-6-S & 122 & & 440 & & 151 & \\
\hline
\end{tabular}

According to table 1 the strengthening effect for specimens C-3-0 and C-4-0 was $172 \%$, for specimens C-5-S and C-6-S - 146\%. The strengthening effect decreases when the structure is under load during strengthening process what can be seen from the test results.

\section{Conclusions}

The effect of strengthening by reinforced concrete jacketing proved to be still significant even when the columns were strengthened under service loads ( $70 \%$ of bearing capacity). Bearing capacity increase was 2.6 times while serviceability capacity increase was 1.5 times. The effect was also less then maximum possible determined from the tests of the columns strengthened without initial loading.

\section{References}

1. E. Julio, F. Branco, V. Silva, Prog. in Struct. Eng. and Mat., 9 (2003)

2. A. Meda, G.A. Plizzari, Z. Rinaldi, G. Martinola, Con. Rep., Rehab. and Ret., II, 6 (2009)

3. Y.M.K. Vijaya, G. Siddappa, S. Chandra, IJRET, 4 (2015)

4. C. Talbot, M. Pigeon, D. Beaupre, D. Morgan, ACI Mat. J., 91, 7 (1994)

5. D. Stoppenhagen, J. Jirsa, L. Wyllie, ACI Str. J., 92, 11 (1995)

6. S. Sugano, New Zeal. Nat. Soc. for Earthq. Eng., 14, 14 (1981) 